\title{
Transapical Off-Pump Neochord Implantation in Case of Severe Mitral Regurgitation
}

\author{
Uldis Strazdins*, **, Gvido Janis Bergs**, Martins Kalejs*, **, Indra Vilumsone* \\ *Paul Stradins Clinical University hospital, Riga, Latvia \\ ** Riga Stradins University, Riga, Latvia
}

\begin{abstract}
Summary
Mitral regurgitation is common valvular heart disease and a major cause of congestive heart failure and death. It is most often associated with degenerative changes in mitral valve which leads to valve prolapse. Transapical off-pump mitral valve repair is a new minimally invasive procedure to treat mitral regurgitation. Here we report 64-year old female who suffered from grade III mitral regurgitation due to ruptured chorda and posterior leaflet P2/P3 segment prolapse. During surgery 4 artificial chordae were implanted and postoperative echocardiography results showed minimal residual grade I mitral regurgitation, therefore significant clinical improvement can be achieved with minimally invasive approach.
\end{abstract}

Key words: mitral valve regurgitation, transapical mitral valve repair, Neochord, artificial chordae

\section{AIM OF THE DEMONSTRATION.}

The aim of the demonstration is to present new innovative minimally invasive procedure to treat degenerative mitral valve regurgitation due to valve prolapse or leaflet flail.

\section{CASE REPORT.}

A 64-year-old female was admitted to university hospital's cardiac surgery department for elective transapical mitral valve repair using NeoChord DS 1000 system (Figure 1). Transthoracic echocardiography (TTE), which was performed 3 months before surgery, showed left atrial enlargement (LA $-45 \mathrm{~mm}$ ) and increased right atrial area (RAA - $24 \mathrm{~cm}^{2}$ ). Transoesophageal echocardiography (TEE) 1 month later revealed posterior leaflet P2/P3 segment prolapse with eccentric mitral regurgitation (Grade III) and $9 \mathrm{~mm}$ long ruptured chorda fragment attached to the posterior leaflet. Tricuspid regurgitation (Grade II) was also evident. Furthermore, patient had some comorbidities such as chronic heart failure (NYHA class II), paroxysmal atrial fibrillation and varicose veins of lower extremities.

Off-pump transapical mitral valve repair surgery was performed via left mini-thoracotomy in the fifth intercostal space. NeoChord DS 1000 system device was loaded with polytetrafluoroetylene (ePTFE) suture and its specific needle. After selective left lung exclusion, two perpendicular purse-string sutures were placed on the lateral aspect of the left ventricular apex and a small left ventriculotomy was performed. Further device was inserted in the left ventricle and the apical purse-strings were tightened in order to minimize blood leakage. Device was guided towards left atrium with 2D TEE and visual control was switched to 3D TTE when it crossed mitral valve. Intraoperative TEE prior chordae implantation confirmed previous echocardiographic findings (Figure 2A, 2B). When exact location of prolapsed segment was identified, the jaws of device were opened and leaflet was grasped. Correct leaflet capture was identified when all four fibre optic lights on the monitor turned from red to white. Furthermore, captured segment of leaflet was penetrated with needle and ePTFE suture was placed. Implantation procedure was repeated four times to prevent whole segment from prolapsing and after determination of proper length and tension with 2D TTE, purse-string sutures were tied and neochords were secured on the apex of heart. Total surgery time was 110 minutes and 4 artificial chordae were implanted during procedure. After implantation of artificial chordae TEE indicated no or minimal residual MR (Figure 3). Postoperatively during intensive care unit (ICU) stay patient had several atrial fibrillation episodes which were managed with Amiodarone. Further postoperative period was uneventful. Compared to preoperative echocardiographic findings control TTE 1 week after surgery showed minimal residual MR (grade I) and decreased tricuspid regurgitation (grade I/ II). Patient was discharged on the $7^{\text {th }}$ postoperative day.

\section{DISCUSSION.}

Mitral regurgitation (MR) is the most frequent valvular heart disease in USA and second most common valvular heart disease in Europe requiring surgery and a major cause of congestive heart failure and death $(3,8)$. Most frequent etiology of MR in last decades has shifted from rheumatic fever, which is the leading cause in low-income countries, to degenerative causes in industrialized countries due to reduction of rheumatic fever incidence and increased lifespan $(3,6,10)$. Degenerative MR is most often associated with mitral valve prolapse, which occurs due to elongation or rupture of the chordae, resulting in abnormal systolic valve movement into the left atrium $(4,13)$.

American College of Cardiology and American Heart Association (ACC/AHA) and European Society of Cardiology and European Association for CardioThoracic Surgery (ESC/EACTS) guidelines suggest that symptomatic patients with severe MR (ACC/AHA: stage 
D, left ventricular ejection fraction (LVEF) $>30 \%$; ESC/ EACTS: LVEF $>30 \%$, left ventricular end-systolic diameter (LVESD) $<55 \mathrm{~mm}$ ) should be advised to undergo mitral valve surgery (I class recommendations, evidence level B). The main treatment option for symptomatic patients with severe MR remains conventional surgical repair or replacement. Elderly patients and patients with left ventricular (LV) dysfunction or significant comorbidities has high operative mortality and morbidity, therefore conventional mitral valve surgery for these patients is often denied $(5,7,12)$.

Transapical artificial chordae implantation using NeoChord DS 1000 system (NeoChord, Inc., Eden Praire, Minneapolis, Minnesota, USA) is an innovative procedure aimed to correct degenerative mitral regurgitation on beating heart without cardiopulmonary bypass. The procedure is performed under direct $2 \mathrm{D} / 3 \mathrm{D}$ transesophageal echocardiographic (TEE) guidance to ensure correct implantation and adequate tension of artificail chordae $(2,11)$. Early results of Neochord procedure show substantial clinical improvement of MR in majority of patients and low complication or reoperation incidence $(1,9)$.

In conclusion we present a case of minimally invasive approach to repair mitral valve prolapse which have showed promising early results with significant clinical improvement and low complication and reoperation rates.

\section{Conflict of interest: None}

\section{REFERENCES}

1. Colli A, Manzan E, Zucchetta F, Bizzotto E, Besola L, Bagozzi L, Bellu R, Sarais C, Pittarello D, Gerosa G. Transapical off-pump mitral valve repair with Neochord implantation: Early clinical results// Int J Cardiol, 2016; 204:23-28

2. Colli A, Manzan E, Zucchetta F, Sarais C, Pittarello D, Speziali G, Gerosa G. TEE-Guided Transapical Beating-Heart Neochord Implantation in Mitral Regurgitation// JACC Cardiovasc Imaging, 2014; 7: 322-323

3. Iung B, Baron G, Butchart EG, Delahaye F, GohlkeBärwolf C, Levang OW, Tornos P, Vanoverschelde JL, Vermeer F, Boersma E, Ravaud P, Vahanian A. A prospective survey of patients with valvular heart disease in Europe: The Euro Heart Survey on Valvular Heart Disease// Eur Heart J, 2003; 24: $1231-1243$

4. Levine R, Triulzi M, Harrigan P, Weyman A. The relationship of mitral annular shape to the diagnosis of mitral valve prolapse// Circulation, 1987; 75: 756-67

5. Mirabel M, Iung B, Baron G, Messika-Zeitoun D, Détaint D, Vanoverschelde JL, Butchart EG, Rayaud P, Vahanian A. What are the characteristics of patients with severe, symptomatic, mitral regurgitation who are denied surgery?// Eur Heart J, 2007; 28: 1358-1365
6. Monin JL, Dehant P, Roiron C, Monchi M, Tabet JY, Clerc P, Fernandez G, Houel R, Garot J, Chauvel C, Gueret P. Functional assessment of mitral regurgitation by transthoracic echocardiography using standardized imaging planes diagnostic accuracy and outcome implications// J Am Coll Cardiol, 2005;46: 302-309

7. Nishimura RA, Otto CM, Bonow RO, Carabello BA, Erwin JP 3rd, Guyton RA, O'Gara PT, Ruiz CT, Skubas NJ, Sorajja P, Stundt TM 3rd, Thomas JD. 2014 AHA/ACC Guideline for the Management of Patients with Valvular Heart Disease: A Report of the American College of Cardiology/American Heart Association Task Force on Practice Guidelines. J Am Coll Cardiol. 2014;63: 57-185

8. Nkomo VT, Gardin JM, Skelton TN, Gottdiener JS, Scott CG, Enriquez-Sarano M. Burden of valvular heart diseases: a population-based study//Lancet, 2006; 368: 1005-1011

9. Rucinskas K, Janusauskas V, Zakarkaite D, Aidietiene S, Samalavicius R, Speziali G, Aidietis A. Off-pump transapical implantation of artificial chordae to correct mitral regurgitation: early results of a single-center experience// J Thorac Cardiovasc Surg, 2014; 147:95-99

10. Seckeler MD, Hoke TR. The worldwide epidemiology of acute rheumatic fever and rheumatic heart disease//Clin Epidemiol, 201 1;3: 67-84

11. Seeburger J, Borger MA, Tschernich H, Leontjev S, Holzhey D, Noack T, Ender J, Mohr FW. Transapical Beating Heart Mitral Valve Repair//Circulation, 2010; 3: 611-612

12. Vahanian A, Alfieri $\mathrm{O}$, Andreotti F, Antunes MJ, Baron-Esquivias G, Baumbartner $\mathrm{H}$, Borger MA, Carrel TP, De Bonis M, Evangelista A, Falk V, Iung B, Lancellotti P, Pierard L, Price S, Schäfers HJ, Schuler G, Stepinska J, Swedberg K, Takkenberg J, Von Oppell UO, Windecker S, Zamorano JL, Zembala M. Guidelines on the management of valvular heart disease// Eur Heart J, 2012;33: 2451 - 496

13. Yu HT, Moon J, Yang WI, Shim CY, Lee S, Chang BC, Hong GR, Ha JW. High Prevalence of Unrecognized Chordae Tendineae Rupture in Mitral Valve Prolapse Patients Undergoing Valve Replacement Surgery// Can J Cardiol, 2013;29:1643-48

\section{Address:}

Uldis Strazdins

Department of Cardiac surgery,

Pauls Stradins Clinical University hospital,

Pilsonu iela 13, Riga, LV-1002, Latvia

E-mail: uldis.strazdins@stradini.lv 

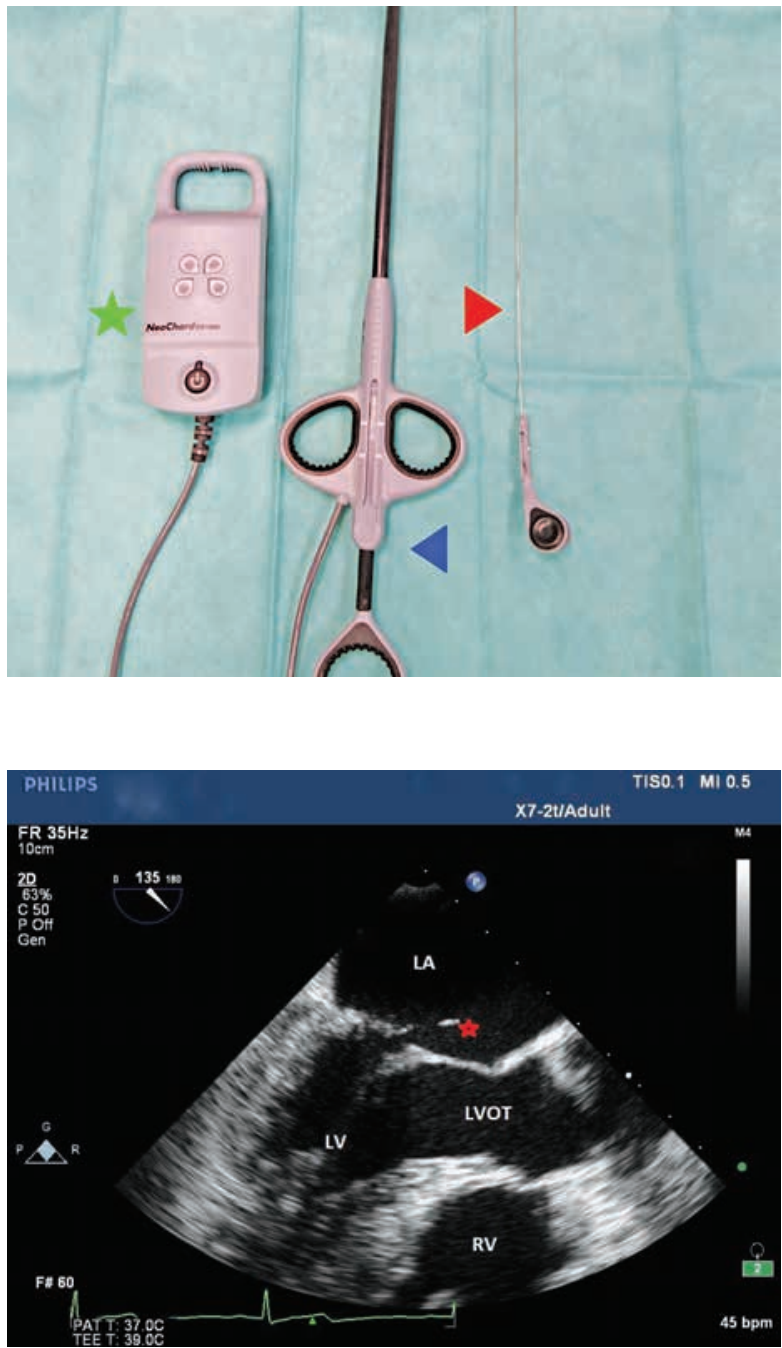

Fig. 1. NeoChord DS 1000 system. Artificial chordae delivery device with two adjustable jaws for leaflet grasping (blue arrow), leaflet capture comfirmation display with four fibre optic lights (green star) and re-usable needle for leaflet penetration (red arrow)

Fig. 2. Intraoperative 2D transoesophageal echocardiogramm (TEE) in ME LAX MV wiew prior chordae implantation. 2A, TEE revealing $9 \mathrm{~mm}$ long ruptured chorda fragment attached to posterior leaflet (red star). LA- left atrium, LV - left ventricle, LVOT - left ventricular outflow tract, RV- right ventricle. 2B, TEE in colour Dopler mode shows regurgitant blood flow into LA during late ventricular systole (green arrow)

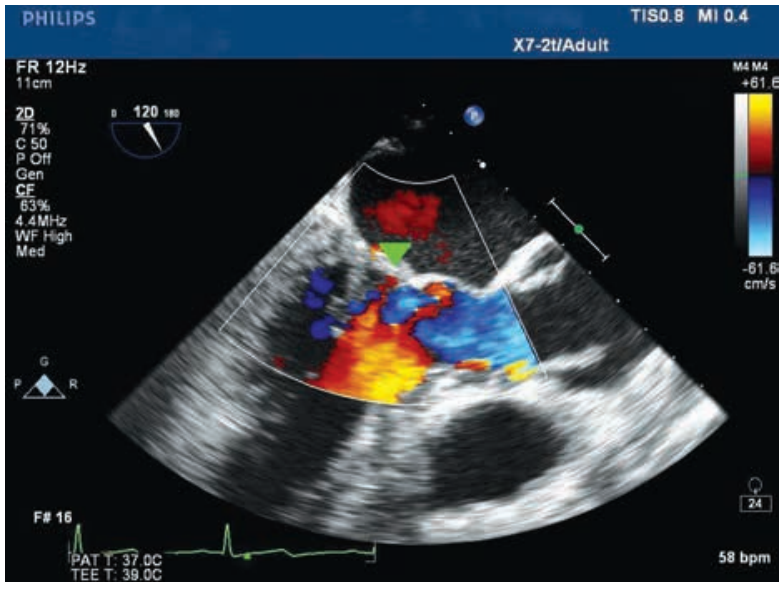

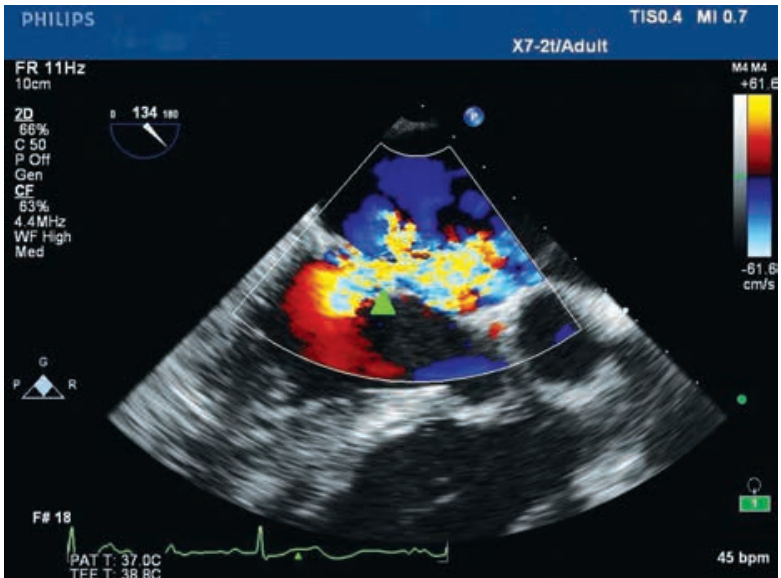

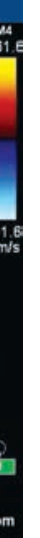

